\title{
The Strategy to Improve the Profession Competence through Knowledge Management to Achieve Corporate Performance
}

\author{
Umi Rusilowati, Hadi Supratikta, Yoke Prima Hendrawan \\ Universitas Pamulang \\ Dosen00061@unpam.ac.id
}

\begin{abstract}
Construction consultancy services in running its business is highly dependent on the competence of professional excellence and ease of getting access to the knowledge of professionalism to achieve the corporate performance. The purpose of this study is improving professional competence, how to establish optimal management profession competency-based knowledge, and how to monitor the effective achievement of the company's performance. That study used descriptive qualitative method in which the significance of research using a triangulation method with a case study on one of the Construction Consulting Services Company in Indonesia. The findings and the recommendation is to revise aspects of growth strategy by increasing the quantity and quality of professional experts with primary expert certificate, aspects of differentiation strategy by creating management information systems knowledge-based professional competence and aspects of the low cost strategy by implementing the concept of the Balanced Score Card combined with Du Pont analysis that can describe the overall performance of the organization.
\end{abstract}

Keywords - professional competence, knowledge management, enterprise performance, Balanced score card, du pont analysis.

\section{INTRODUCTION}

The concept of strategy is a profitable way to achieve the goals in accordance with the direction and scope of each phase of work through the configuration of the resource potential, with rejuvenation/ improvement corporate cycle that remain in the growth phase [1].

The concept of profession competence is the competence (attitude, knowledge and skills) that shown by professionals worker who excellent in their field of profession expertise (in construction), both technical (hard competency) and communicative (soft competency) which has a classification level of expertise consists of the new/ notice/ awareness level, the beginner/ knowledge level, the competent/ skill level, the proficient/ mastery level, and the expert level [2].

The concept of knowledge management is an organization's efforts to transform tacit knowledge into explicit knowledge that can be identified, created, described, stored, managed, developed and deployed, so it can be reused and studied in depth by anyone in need, both within the organization and outside organization. Davenport [3]
Theory of a strategy to improve profession competence through knowledge management to meet the corporate performance, is an effective way and beneficial to improve the quality of attitudes, knowledge and skills that their field of profession expertise, as well as meet the resource configuration professional in a field of work, through the process deepening the knowledge that has been stored, managed, developed and distributed/ shared in the system, which can be used again by each individual professional to work with superior accordance with the direction and scope of the stages of work, so as to meet the level of achievement/ performance to suit the achievement of goals and targets in the given time period [4].

Facts about the profession competence on one of The Construction Consulting Services Corporate in Indonesia is the amount of primary experts who have primary expert certificate just only 10 people of the 81 people who certified or from all employees 912 people, which they must obtain a target projects worth 174 billion.

Facts about knowledge management is need a facilities of management information system (MIS) as well knowledge sharing culture of profession.

Facts about the corporate performance is an improved performance although still have increase the risk of carryover and there is not yet of balanced score card (strategy map) to monitor the performance of the corporate.

Problems between the concept and the fact of profession competence is the amount of primary experts who have primary expert certificate is still more less if compared than the project target which must be obtained, so it is very necessary education, training and certification to the under of primary expert certificate, so the quality of experts can continues to improve.

Problems between the conceptual and factual knowledge management in is that a lot of experts still have difficulty in searching for data, information and knowledge of professions which use to improve the character/ identity and ability in solving of more problems of professionalism, so it is necessary of management information system (MIS) to distribution of knowledge and establish a culture of knowledge [5]. 
Problems between the concept and the fact the corporate performance is the risk of the workload and the carry-over will be continues to increase every year, but still have to maintain the quality of resource competencies professional and to achieve the target of return on Investments (ROI) or return on equity (ROE) of corporate, so it is necessary balanced score card that equipped with a financing concept $\mathrm{Du}$ Pont analysis as a strategy mapping to look at/ monitoring all of the corporate performance [6].

The purpose of this study is improving professional competence, how to establish optimal management profession competency-based knowledge, and how to monitor the effective achievement of the company's performance.

\section{THEORETICAL BASIS}

\section{A. Theory of Profession Competence}

Profession competence (attitude, knowledge and skills) that excel in the field of construction consulting services are classified as follows [7] :

- Architecture, consisting of: a) Architects, b) Interior design expert, c) Architectural landscape expert, d) Illumination expert

- Civil, consisting of: a) Building engineers expert, b) Road engineer expert, c) Bridge engineers expert, d) Safety road expert, e) Tunnel engineer expert, f) Flying platform engineer expert, g) Railway engineer expert, h) Pier engineer expert, i) Offshore building engineer expert, j) Large dams engineer expert, k) Rivers and drainage engineer expert 1) Irrigation engineer expert, m) Swamp and beach engineers expert, n) Demolition engineers expert, o) Building maintenance and care expert, p) Geotechnical expert, q) Surveyor expert

- Mechanical, consisting of: a) Mechanical engineers expert, b) Air plan system and refrigeration engineers expert, c) Plumbing and mechanical pumps engineers expert, d) Fire protection engineers expert, e) Building transportation engineers expert

- Electrical, consisting of: a) Electrical power engineers expert, b) Building electronics and telecommunication engineer's expert, c) Railway telecommunications signal system engineer's expert.

- Environment plan, consisting of: a) Environment engineers expert, b) Regional and urban city plan expert, c) Sanitation and sewage engineers expert) Drinking water engineers expert

- Implementation management, consisting of: a) Construction management experts, b) Project management experts, c) Clean, safety and health construction expert

The overall of profession competence are grouped into several levels of proficiency [8] that is:

- Beginner Expert/Architect (Pratama Expert) is the level of expertise with low complexity,
- Middle Expert/ Architect (Madya Expert), is the level of expertise with moderate complexity.

- Primary Expert/ Architect (Utama Expert), the level of expertise with high complexity, (Aprianto \& Jacob, 2013), or have more excellent control, distribute and expert teach to another person [9].

- Knowledge management can be used to manage knowledge flows and enables [10]

\section{B. Theory of Knowledge Management}

Knowledge management is to transform from tacit knowledge into explicit knowledge so can be managed and relearn, it have six core processes [11], these are:

Knowledge goal, Knowledge Identification, Knowledge Acquisition, Knowledge Development, Knowledge Distribution/ Sharing, Knowledge Preservation/ Retention, Knowledge Use/ Utilization, and Knowledge Measurement [12].

The form of knowledge management implementation is the Management Information System (MIS), which can store, process/ manage and distribute of the knowledge so enable to interaction between professional personal, customers and operator to share the knowledge on the systems and processes in corporate, which is done simultaneously, integrative and consistent [13], so can improve a sustainable excellence culture for the corporate and very difficult to replicate [14] can minimize of risk, improve of efficiency, and improve of innovation [15], by apply of the right of information service speed, complete and accurate to realize the goals of the organization [16], using the electronic based of management information system so can be easy to access by anyone who needs [17].

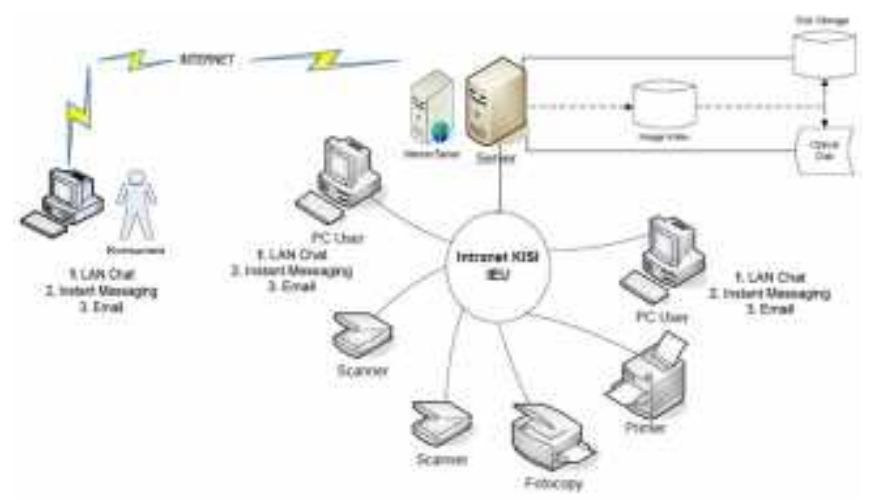

Fig. 1. The Electronic Base of MIS Process

a. source: Haripradono, 2015

\section{Theory of Corporate Performance with Balanced Score Card Method}

The corporate performance is the level of resulting achievement/ working performance in a specific time period by utilizing the available resources in order to realize the corporate goals, which can be measured using a method of 


\section{Asuneses PRESS}

measuring tool which able to describe, compare and projected of condition in the corporate at a specific time period [18]

The method used is a strategy map/ Balanced Score Card (BSC) method that is a method for translating the vision, mission, goals, objectives and strategies of the corporate (both aspects of the tangible and intangible) into a flow chart that describes the implementation of the entire performance of the corporate [19]

The concept of the Balanced Score Card (BSC) can be seen as follows [20].

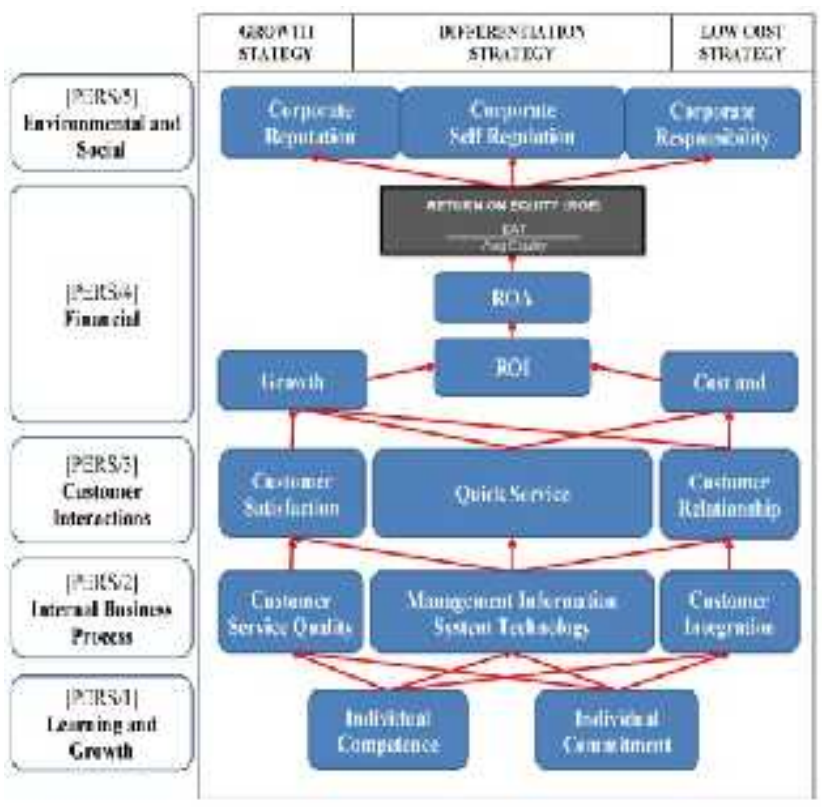

Fig. 2. Balanced Scorecard (BSC)

b. source: Mulyadi in Kuncoro, M., 2006

Each of these perspectives need financing, where the proportion of the amount of funding can be put on the Du Pont tree formula, as follows [20].

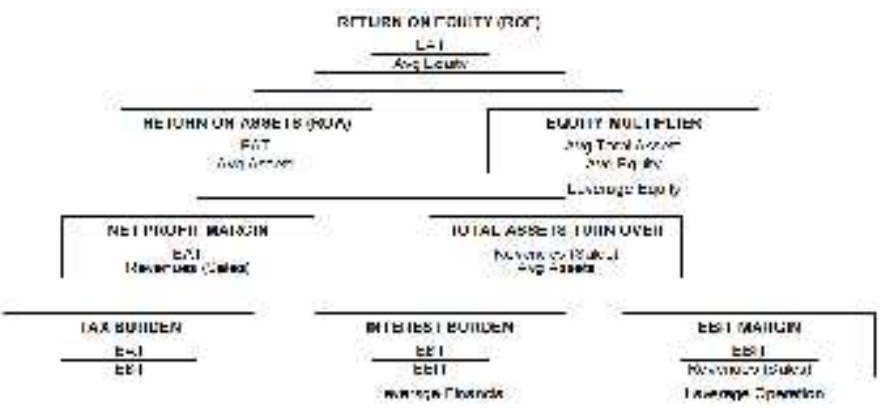

Fig. 3. Du Pont Tree Formula

Source: Internet, 2014

ROE/ return on equity is the value to know about the corporate assets that can be used as a dividend to the investor (ratio of net income to total equity). ROE value is equal to the ROI (Return on Investment) when the value of the corporate assets are invested only for this company's business, not to invest in other corporate. The investment value here is equal to total assets less investments, so all forms of investment to other corporate not incorporated in value. ROE has two components, namely ROA (Return on Assets) or the rate of return on assets which is the percentage of net income to total overall assets, than equity multiplier which is the average ratio of total assets to equity [22].

Each component in the Du Pont analysis have each character also, so when the Du Pont analysis is juxtaposed/ synchronized with the Balanced Score Card, it can be obtained the compositions which can be adapted to each character. This pairing/ equalization is very useful to know about the proportion of financing and the amount of risk on each of the existing components. Here the concept of Balanced Score Card that has been juxtaposed with the concept of the Du Pont tree [23]

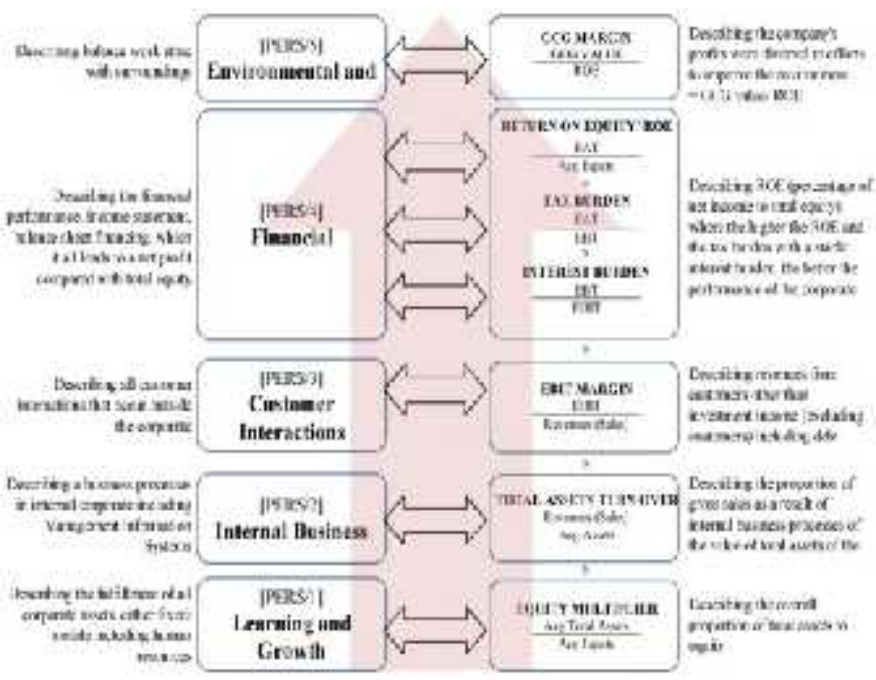

Fig. 4. The Pairing Concept of BSC \& Du Pont

From the chart, it can be seen that the financing percentage/ proportion of each the BSC components are the same as the percentage of the Du Pont components. Perspective of Learning and growth which consists of the fulfillment of all corporate assets, both fixed and moveable assets, including human resources, very suitable when using the value of the equity multiplier because it describes the proportion of total assets to total equity [24]. Perspective of internal business process that consists of all business processes in the internal corporate, including of knowledge management system, very suitable when using the value of total assets turn over because it describes the proportion of gross sales as a result of internal business processes to the value of corporate assets [25]. Perspective of customer which consists of all customer interactions that occur outside the corporate, very suitable when using the value ebit margin because it describes the overall value of earnings before plus/ cut interest and tax on gross sales, which it shows the amount of income earned from customers in comparison with the amount of revenue generated from other investments (non-customers) including debt [26]. Perspective of financial is comprised of a profitability analysis which showed a net profit compared with a total equity value, very suitable when using ROE value, tax burden and interest burden. The higher of ROE and tax burden with stable interest expenses or equal to one, will be better the 


\section{$\triangle$ ATLANTIS PRESS}

performance of the corporate. Then perspective of the environmental and social as improve of good corporate governance/ GCG that consists of balancing of work ethic with the environment, it can be seen through the creation of GCG performance margin, that is the ratio of GCG with ROE.

In detail, the chart concept of the Balanced Score Card that have been juxtaposed with Du Pont tree is as follows [27]:

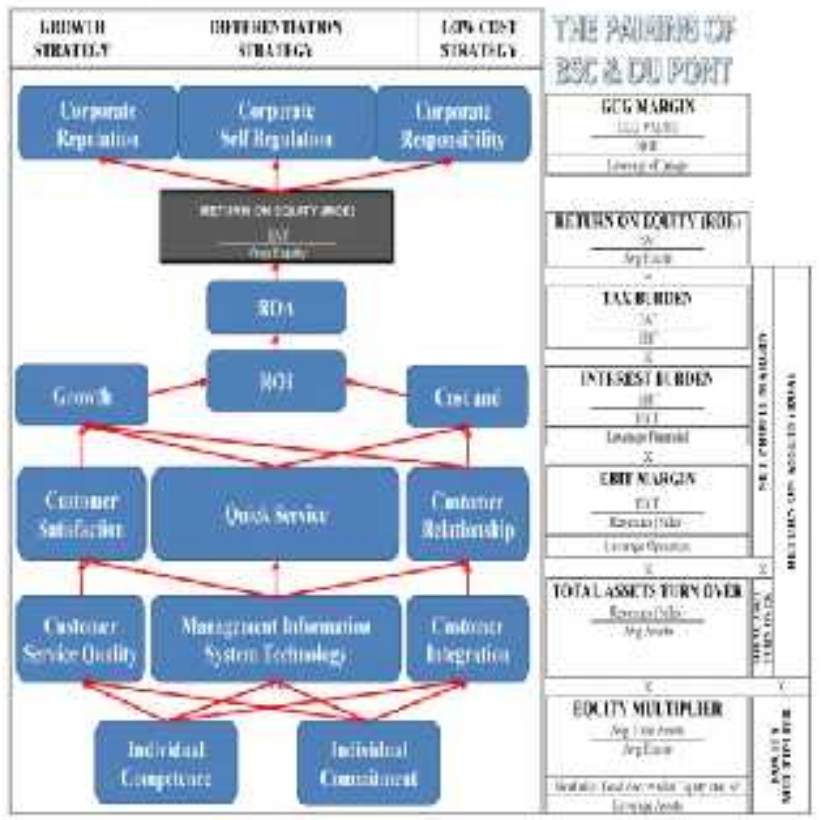

Fig. 5. The Pairing of BSC \& Du Pont

\section{RESEARCH METHODOLOGY}

The framework is to be start from study of the performance through interviews, questionnaires, photographs, Corporate Long Term Plan/ CLTP (RJPP) in 2014-2015, Corporate Budgeting Plan/ CBP (RKAP) in 2015, Financial Statements Audited in 2010-2014, list of permanent experts and list of corporate experience [DATA], then look for a gap/ mismatch between facts and hope/ in theory, and created a proposition as the focus of this study [28].

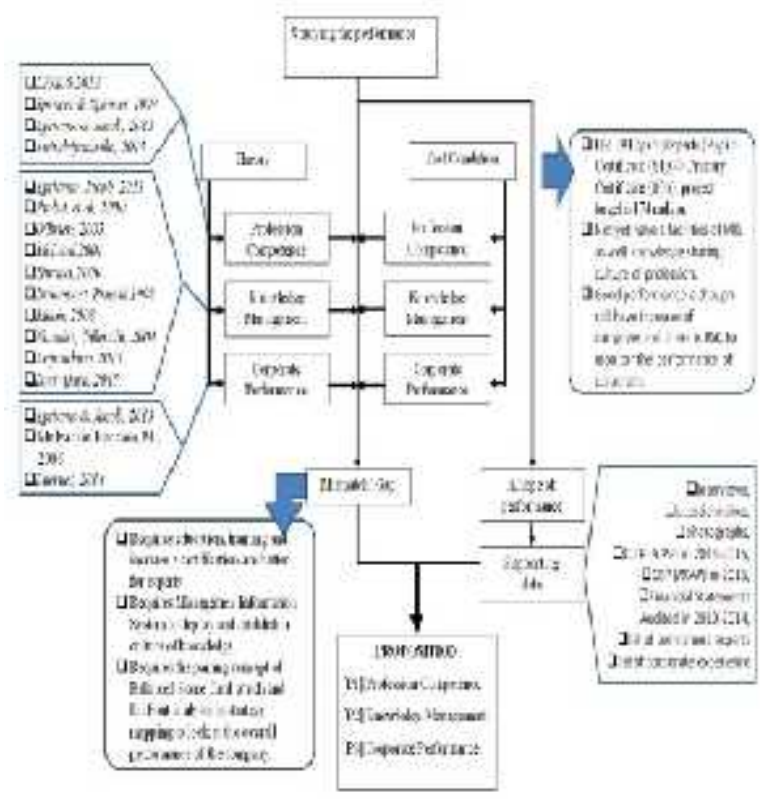

Fig. 6. The Framework

The proposition is as follows [29]:

- More advanced level of fixed expert of profession competence will more add the professional competitive advantage in the market of construction services business. [P1]

- Competency based knowledge management that a good of manage, will be able to improve the knowledge cultural, so can help for the achievement of the corporate performance. [P2]

- The corporate performance can be monitored and can be fulfilled through the method of Balanced Score Card. [P3]

The method used is descriptive qualitative method with a single case study, which description of the professional competence, the competency based knowledge management and the implementation of Balanced Score Card as the effort to monitor the fulfillment of the corporate performance. To support the accuracy of the data, perform the analysis of [DATA] and expert judgment that emphasizes of the interactive discussion, and group behavior, especially for competence, knowledge management and the implementation of the Balanced Score Card (BSC) to monitor the fulfillment of the corporate performance [30]. The following flow chart of the study. 


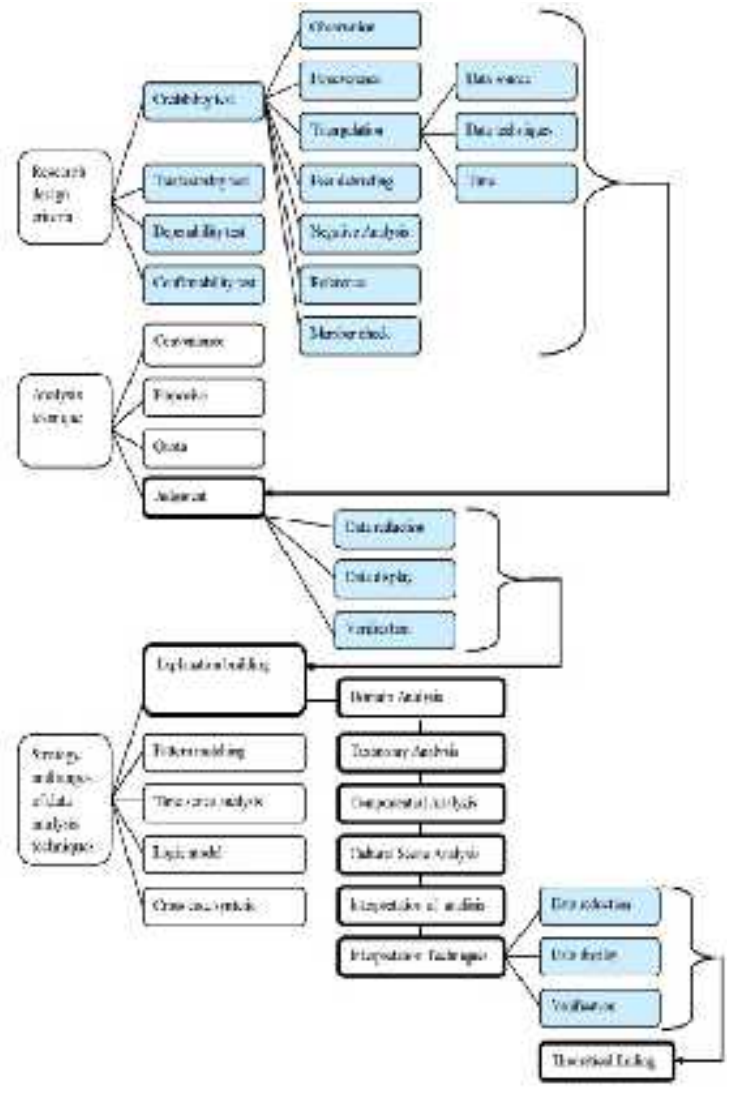

Fig. 7. Flow Chart Research

\section{FINDING \& DISCUSSIONS}

Analysis of Domain $[\mathrm{AD}]$, that is analysis to obtain an overview of the data related to the focus of research, which includes the cause, reason/ purpose, rational, sequences, type, place, method, use, and tools/ attributes/ issues do the research.

The next step is to create the domain analysis which appropriate of focus of the problem or proposition, which included details of domain and semantic relationships with the domain which appropriate the proposition.

\section{[P1] Domain analysis of propositions 1}

Some of the semantic relations of profession competence that are:

Cause the need for profession competence .due/ purpose of the improvement of profession competence, rationale/ reasons of why the profession competence, sequence of the efforts to increase profession competence, type of profession competence, place to implement the profession competence, method of the profession competence distribution, use of the legality of competence, and tools/ attribute to support the competence.

\section{[P2] Domain analysis of the proposition 2}

Some of the semantic relationships of knowledge distribution that are:
Semantic relationships between these domains can be concluded that cause the need for knowledge management is to make a costs evicienly to face competition of competitive advantage, by speeding up the knowledge service through a profession management information system (MIS) with electronic base that can implement, store and process the tacit and explicit knowledge into a professions knowledge concept so can be used as a source of profession knowledge that are ready to be distributed, which the goal is to create a profession competitive advantage.

\section{[P3] Domain analysis of propositions 3}

Some of the semantic relationships of corporate performance using the balanced score card (BSC) that are:

Because the need for BSC, Due/ destination of BSC, Rationale/ reasons of why the BSC is very important, Sequence of workflow strategy of corporate performance, Type/ dimension of BSC, Objective place for to implement the BSC strategy, Method to apply the corporate performance achievement, Use the performance benchmark, and Tools/ attributes

Semantic relationships between these domains can be concluded that cause the need for BSC method for assessing the corporate performance is due the BSC describe the workflow and strategy map of the corporate as a whole by displaying a complete perspective so that they can see the performance of the corporate as a whole. BSC can be combined with Du Pont analysis to establish the proportion of financing each perspective on the BSC, so it's to be more effective and more efficient.

It was concluded that the method of BSC is needed to see the workflow, the target attainment and strategies achieve the corporate performance and be classified it into [PERS/1], [PERS/2], [PERS/3], [PERS/4], [PERS/5], whether it is leading to the growth strategy [GRW], differentiation strategy [DIFF] and low cost strategy [LOW], and can be paired well with the Du Pont analysis to get an description of the financial performance in each perspective.

In the taxonomic analysis, also conducted reconstruction of the problem, which in that reconstruction is grouped to the sub domains that have linkages between the domains, so that it becomes more concise and directional and can figure out the problem/gap is more focused. The issues of the problem/ gap that occur for each of the propositions can outlined below.

\section{[P.1] Construction Analysis Groove Proposition 1}

Gap: the availability of the Primary Experts only Architect, Building Health Care and Maintenance Expert, Geotechnical Expert, Surveyor Expert, Sanitation and Waste Engineers Expert, and Construction Management Expert, when in fact to offset the number of projects handled requires the availability of the primary experts even more. [CAG/P1/GAP]

\section{[P.2] Construction Analysis Groove Proposition 2}

Gap: not available yet of infrastructure, bank data \& knowledge sharing mechanisms for stakeholders, either among divisions, professions, providers, users and suppliers, so it has not yet formed a culture of sharing knowledge, but to support 
the performance of the entire profession in every branch of the corporate is very necessary to unites the viewing direction/ the planning concept that can be easily accessed by the respective divisions, branches and professions. [CAG/P2/GAP]

\section{[P.3] Construction Analysis Groove Proposition 3}

Gap: not available yet of Strategy Map/ Balanced Score Card (BSC) when in fact the BSC is very necessary to unites the direction of view of the corporate strategy [GRW] [DIFF] [LOW]. In accordance with the focus of the problem, the Profession competence grouped into the [GRW] on the [PERS/1]. Knowledge management grouped into the [LOW] on the [PERS/2]. Quality control, cost and time grouped into the $[\mathrm{DIFF}]$ on the $[\mathrm{PERS} / 3]$. Profitability analysis Du Pont grouped into the [DIFF] on the [PERS/4]. The environmental controlling value of the corporate which is based on CSR grouped into the [LOW] on the [PERS/5]. [CAG/P3/GAP]

Analysis of Componential [AC], by selecting the contrasts domain to describe the gap, and it had be choose the architect competence domain which in accordance with the competence of the researchers themselves.
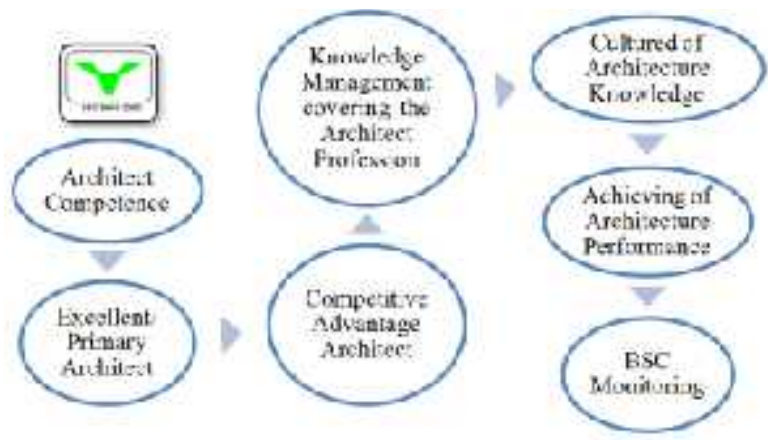

Fig. 8. Flow Chart of Proposition the Competency of Architects

The following componential analysis of each proposition.

[P1] Componential Analysis of Proposition 1

The purpose is to locate the source of the gap [CAG/P1/GAP] with a domain focus of competency requirements of Architect.

1.1 Mastering 13 grains of competency standards of Architect which established by professional associations, the Association of Indonesian Architects (IAI), that are : ARS 01) Architectural Design (consist of aesthetic and technical requirements), ARS 02) Knowledge Architecture (consist of knowledge of architectural history and theory of architecture), ARS 03) Knowledge of Art, ARS 04) Planning and Urban Design (consist of urban planning and urban design), ARS 05) The relationship between Man, Building and Environment (consist of the relationships of the human and the building, the building and the environment, as well the humans and the environment), ARS 06) Knowledge of Carrying Capacity of the Environment, ARS 07) The role of architects in society, ARS 08) Preparation Work Design (consist of methods of data collection and preparation of program design), ARS 09) Understanding the problem interdisciplinary (consist of knowledge of systems structure and construction, as well knowledge of system mechanical, electrical, electronics and plumbing), ARS 10) Knowledge Physical and Building Physics (consist of the comfort factor in building and protection factor building on the climate), ARS 11) Implementation of Budget Constraint and Building Regulations (consist of knowledge regarding the budget building and knowledge building regulations), ARS 12) Knowledge of Industry Construction In Planning, and ARS 13) Knowledge of Project Management. [AC/P1/STANDARD]

1.2 Complement the legal aspect [AT/P1/USE] The higher the classification, the more reliable to plan buildings or areas with a high level of complexity, may plan a building with a height of more than 8 floors, and be planned restoration of heritage buildings, and are entitled to a license Actors Technical Building (IPTB) for class A. [AC/P1/LEGAL]

1.3 Position of Architect expert, that a Primary Architect can be a project leader and can create an idea, a concept and a good professions system. Meanwhile a Middle Architect can be a Project Expert and help a Primary Architects in realizing the concept. Then Beginner Architects can be a junior Architect expert. [AC/P1/TITLE]

1.4 Conditions of Architect Expert, that a Primary Architect are very limited and be a structural position, which the Primary Architect certificate indispensable to the auction, a Middle Architect lead projects of high complexity more than one and without the help of Primay Architects, then a Beginner Architects also lead projects of high and medium complexity sometimes. There are many architects who worked on the project have not been certified yet. There is a gap here, the all of ideas and concepts submitted to the Middle and Beginner Architect up to the high complexity, so the distribution of Architect knowledge can obstructed. [AC/P1/CONDITIONS]

1.5 Primary Architech Competence is an expert who has competence in designing and supervising the implementation of the building with high complexity, the restoration of buildings, heritage buildings, urban and built environment as well research the projects that include aspects of aesthetic, cultural, and social. Consists of two characters, that is the level of the primary expert who has the ability to create ideas, lead projects, crreate the teamwork, as well the level of the primary expert who has the ability to teach, create a literature of architecture and continues to provide profession education. [AC/P1/MAIN]

1.6 The competitive advantage of architect is an architect who has the excellent competence and has a different characteristics from the other in terms of leading, designing and supervising the implementation of the building with high complexity and varied, the restoration of buildings, heritage buildings, urban and built environment as well research studies, which includes the aspects of aesthetic, cultural, and social. Than be able to understand, resolve and combines the whole obstacles and opportunities, both internally and externally, into a unified force of concept that has a good bargaining power (SWOT analysis). [AK/P1/SUPERIOR]

On this analysis, many of gaps found between the primary architect availability requirements with the fact. Many experts 
are still at the level of beginner architect and has not been certified expertise. The solution of architect competence so that can be sustainable, both regarding responsibility, loyalty and competence distribution, then the Primary Architect who many live in the headquarters, should be able to provide education and professional training continuously to all branches, and prepare the certification of architect according to its level until the Primary Architect in all branches, as well complement the competencies that still not exist for the achievement of business targets that have been planned, to create the competitive advantage of architect, it requires the management information system (MIS) and the reward system that more better. The corporate must be able to create a primary architect who has an excellent competence and strength characteristics of leading and implementing its professionalism. [AK/P1/SOLUTION]

\section{[P2] Componential Analysis of Proposition 2}

The purpose is to locate the source of the gap [CAG/P2/GAP] with a domain focus of competency requirements of Architect with a domain focus of competency requirements of Architect in terms of implementing knowledge management through teh management information system (MIS), that is:

2.1 The relations of an architect knowledge distribution, beginning from Primary Architects provide knowledge transfer to Middle Architect (one way) and the other Primary Expert across disciplines (two way), Middle Architects provide knowledge transfer to Beginner Architect (one way) and the other Middle Experts across disciplines (two way), then Beginner Architects also provide knowledge transfer to the other Beginner Experts across disciplines (two way), so that it can create the unity of thinking in implementation their profession competence. [AC/P2/FUNCTIONAL]

2.2 Relations distribution of knowledge among architects and among Division, wherein Primary Architect should be in the ranks of senior structural, such as Board of Director (BOD), Board of Profession or the Functional Position, then provide knowledge transfer between divisions and functional like as Head of Division, Regional Head, Branch Manager and other Primary Architect on the project. From Head of Division then continue the transfer of knowledge to the Section Chief and the Midlle Architect/ Middle Expert other? From Section Chief then continue the transfer of knowledge to the Beginner Architects/ Beginner Expert other. From the Primary Architect then continue the transfer of knowledge to Middle Architects and other Primary Experts across disciplines. From the Middle Architects then continue the transfer of knowledge to Beginner Architects and other Middle Expert across disciplines? Last from the Beginner Architects then continue the transfer of knowledge to other the Beginner Experts and the experts who have not been certified? [AC/P2/STRUCTURAL]

2.3 Endurance Primary Architect in resolving problems is longer work with weights higher employment than both the Middle Architect and the Beginner Architect, as contained in the following graph. [AK/P2/ENDURANCE]

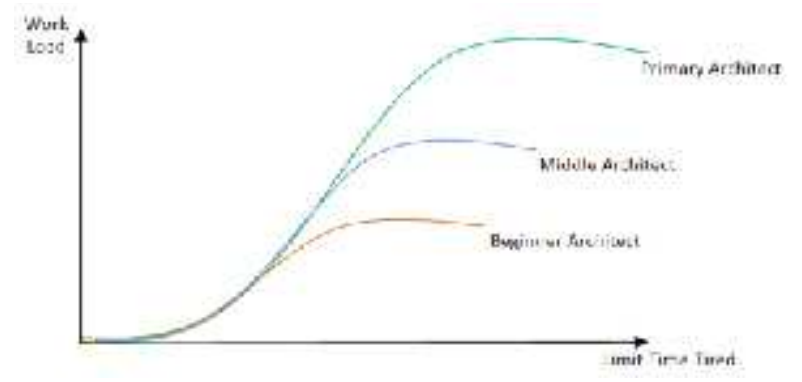

Fig. 9. Graph Endurance Expert Profession

2.4 Responsibilities of the Primary Architect competence in all branches of according to the target business with an emphasis on the property sector, construction consulting services and energy consulting services, that is : 1) Primary Architect from the headquarter provides a professional education and training continuously to all branches of and prepare the certification program of Primary Architect. 2) Primary Architect certification process at all branches. 3) Transfer knowledge to the entire Middle and Beginner Architects, as well to all profession disciplines. [AC/P2/RESPONSIBILITY]

2.5 The strategy of knowledge management based on competency as a form of distribution of architects competence, should be started from Primary Architects which must be understand and execute the steps to achieve the architecture knowledge management, that is : 1) Knowledge goal, wherein the Primary Architect must be understand and supervision the vision, goals, performance strategies of high, medium and low impact of corporate related an architecture competence, as well the cost of production and operations to achieve this goal, 2) Knowledge identification, wherein the Primary Architect should master the data, fact, analysis, knowledge architecture and solutions to problems all professional competence, which include [GRW], that is master of knowledge about improved the corporate performance, the profession competitive advantage and the reliable human resources. [DIFF] that is master of knowledge about the property, energy and construction. [LOW] that is master of knowledge about optimization, innovation, certification, investment, banking and strategy of getting a new contract. 3) Knowledge acquisition, wherein the Primary Architect must master of knowledge and good cooperative relationship with the customer, like the owner, the technical team, and the partners, like sources/ speakers/ interviewers, consultants, sub consultants, contractors, sub contractors, and suppliers/ material industry suppliers all disciplines. 4) Knowledge development, wherein the Primary Architect must follow the research and development of the architecture, knowing all disciplines of research and development of professional competence, knowing the structural and functional workflow, and present/ teach the results of research and development of architecture to each branch. 5) Knowledge distribution, wherein the architect must be willing and able to share the competence knowledge to the owner, technical team, speakers, consultants, sub-consultants, contractors, subcontractors, and suppliers, and is able to pour into the Management Information System/ MIS based computerization. 6) Knowledge preservation, wherein the architect must be able to 
select information, save selected information and constantly updates the information, whether the information comes from the cross-division, cross professional competence, customers, partners, and suppliers, so it can be processed into a knowledge architecture is more mature. 7) Knowledge use, wherein the architect must be able to know/ monitor/ measure the success of the project from the pre-auction until the completion of the project, then he can analyze/ measure regulatory developments, strategy and realization of performance across divisions, profession, customers, partners and suppliers, as well capable of creating a performance measurement tools/ mapping that can be seen by all who need (electronic based), namely in the form of Balanced Score Card [AC/P2/STRATEGY]

Many gaps in the process of architecture knowledge distribution for lacking the Primary Architect and other Primary Expert. A good solution is to implement a profession base knowledge management, then had created a system of good Management Information System (MIS) which can access to all stakeholders and is purely electronic, so it can create a good communication, knowledge distribution, cooperation relationship with customers (like owner, technical team and resources) and partner (like consultants, sub consultants, contractors, subcontractors) as well suppliers (like material industry supplier for professional competence of all disciplines). An architect should be able to select information, save selected information and constantly updates the information, whether the information comes from the cross division, cross profession competence, customers, partners, and suppliers, so it can be processed into a more mature architectural knowledge. Corporate must facilitate the Primary Architect to continue to provide training, research and development of architecture to the junior architect and all profession competence in each branch, as well to give the architecture knowledge of to the owner, technical team, speakers, consultants, sub consultants, contractors, subcontractors and supplier. The corporate must also prepare a good electronic management information system (MIS) and can be accessed easily by all stakeholders. [AC/P2/SOLUTION]

\section{[P3] Componential Analysis of Proposition 3}

The purpose is to locate the source of the gap [CAG/P3/GAP] with a domain focus of Architect competency requirements in terms of implementing the BSC, that is:

3.1 Performance of Primary Architect/ Primary Expert greatly affect the formation of the information technology infrastructure and the establishment a model of commitment and corporate culture. Performance of knowledge sharing culture greatly establishment the success of the mastery of management information systems technology and the employee success cycle. Performance monitoring and a good time schedule greatly establishment the customer success cycle and can create the customer relationships. Implementing strategies Du Pont system is helpful to monitor the performance of the corporate and minimize financial risk. A good implementation of CSR continuously will affect the corporate reputation and it can create the flexibility regulatory of the corporate. The Primary Architects/ Primary Expert performance, the knowledge sharing culture performance, monitoring performance and a good time schedule, Dupont system and CSR, simultaneously greatly affect the achievement of the corporate performance, and vice versa achievement of the corporate performance greatly affects the energy/ power of Primary Architect/ Primary Expert performance, and this called the Flow of Performance Achievement. [AC/P3/EFFECT]

3.2 The balanced score card as monitoring tool to achievement of the corporate performance arranged in the form of a matrix, consist of: 1) [PERS/1], [GRW] is a general competence of human resources and a professional competence of Primary Architects/ Expert, [DIFF] is an infrastructure of information technology (IT), [LOW] is a commitment and corporate culture, which is the responsibility of leader, all Expert under the control of the Board of Profession. 2) [PERS/2], [GRW] is an employees success cycle, [DIFF] is a mastery of management information systems (MIS) technology, [LOW] is an application of knowledge management, which is the responsibility of the Head of Finance and General as well the Head of Marketing and Operations for each of the divisions, regions and branches. 3) $[\mathrm{PERS} / 3],[\mathrm{GRW}]$ is a customer success cycle, [DIFF] is a quality control, cost and time, [LOW] is an establish customer relationships, which is the responsibility of Head of Division, Head of Regional and Branch Manager. 4) [PERS/4], [GRW] is profession and corporate performance, [DIFF] is a profitability analysis Du Pont system, [LOW] is a laverage analysis/ low risk financially, which is the responsibility of Board of Director, commissioner, Internal Trade Union and Bureau , 5) [PERS/5], [GRW] is a corporate reputation, [DIFF] is a corporate regulation, [LOW] is a corporate social value, which is the responsibility of Jurists Expert, Economist Expert and Community Relations Expert. [AC/P3/MATRIX]

The Balanced Score Card is a performance measurement tool which is very complete, can see the grooves of a clear strategy, can be arranged as a matrix and can be combined with other indicators to sharpen the analysis. BOD to be responsible for the overall general corporate activities which can monitored in a Balanced Score Card.

4. Analysis of Cultural Themes, by formulating the theme of universal culture, which each proportion merged into a Balanced Scored Card scheme, concluded:

\section{[P1] Cultural Theme Analysis of Proposition 1}

Profession competence can be inserted into the [PERS/1], in this case the Primary Expert are constantly improving the competence of the profession at the same time to spread the profession knowledge. [GRW], emphasizing the professional competence enhancement for improving the performance of the entire profession competence. [DIFF], emphasizing the performance realization by the information technology system and prioritize services to corporate both headquarter and entire branches. This condition occurs only in the headquarter, although not optimal yet, that is the competence of the architect, geotechnical, surveying, mechanical engineering, engineering and project management of drinking water, whereas in all branches have not optimal yet to use the information technology. The emphasis is only the project 
quantity not project quality. [LOW], emphasizing the corporate commitment for excellent competent, that is: 1) Taking education and training, as well sharing the profession knowledge, 2) active as a member of the profession association or as a Board of Profession, 3) Always enrich the literature and created the literary works profession, 4) Always create a system that many connections between the profession and stakeholders, 5) Capable as leader of several projects. The fifth item is still to be improved of implementation, both at the headquarter and all branches

\section{[P2] Cultural Theme Analysis of Proposition 2}

Knowledge management can be inserted into the [PERS/2], which consists of a knowledge goals, knowledge identification, knowledge acquisition, knowledge development, knowledge distribution, knowledge preservation, knowledge use and knowledge measurement. In the aspect of [GRW], emphasizing the process of the employee's success cycle for all the profession competence. [DIFF], emphasizing on mastery of MIS technology. [LOW], emphasizing the knowledge distribution, that is the profession competence knowledge distribution which consist of sharing across divisions, profession competence, customers, partners and suppliers. The results that the application is still lacking, both at the headquarter and all branches.

Knowledge management is very closely related to customer satisfaction, because the internal and external relations can only be controlled through this knowledge management. Customer control intimately entered in [PERS/3], with a concentration on the implementation of quality control management, cost and time so as to create customer satisfaction. [GRW], emphasizing the priority to customer success cycle. [DIFF], emphasizing the quality control, cost, time, risk, consist of the partnership, quality control, bussiness plan, schedule of work and risk management. [LOW], emphasizing the positive interactions/ relationships/ attention to the customer. The results that the application still has to be improved, both at the headquarter and all branches.

\section{[P3] Cultural Theme Analysis of Proposition 3}

The corporate performance entered in the [PERS/4] which the BSC + Analysis Dupont as control the performance \& proportion of the financing of each components/ perspective. [GRW], emphasizing the corporate performance and the each profession competence performance with achievement gains (ROE, ROI, and ROA). [LOW], emphasizing the low financial risk strategy. [DIFF], emphasizing the profitability analysis of Dupont are juxtaposed with each BSC perspective, that [PERS/1] with Equity Multiplier, [PERS/2] with Total Assets Turn Over, [PERS/3] with Ebit margin, [PERS/4] with ROE, Tax Burden and Interest Burden and [PERS/5] with GCG Margin. The result is the corporate does not have the BSC and the Dupont analysis, whereas the corporate profits can be enhanced optimally through the BSC method, both at the headquarters and all branches.

Financial perspective closely related to improve the image of the corporate in the business environment, government and society, that can referred to a good corporate governance
(GCG) which entered in the [PERS/5], consists of environmental community control intimately by increasing the value, norms and culture of the surrounding community. [GRW], emphasizing the image forming corporate reputation. [DIFF], emphasizing the forming of regulations and corporate standard. [LOW], emphasizing the forming of environment ethical/ cultural. The results that the application must be optimized return, both at the headquarter and all branches.

The strategy of data analysis techniques, expand the analysis with an explanatory concept (Nazir in Pujileksono, 2015), linking theory with issues/ findings obtained (Stringer cited by Sukmadinata in Pujileksono, 2015).

1. Interpretation of Results Analysis, a critical view researchers of the analysis results:

\subsection{Interpretation of Proposition 1}

Requires each profession competence department so the hierarchy of scientific professions to be clear and structured, can be managed independently and be able to reach the each benefits. The work team of those each competence that will fill the several of profession knowledge fasilities and be able to establish cooperation between all profession departments. The best anticipation is to be performed the education and professional training, the certification improvement, and recruitment of certified experts. This applies to all levels of expertise and all profession competence.

\subsection{Interpretation of Proposition 2}

The process of dissemination/ distribution of profession knowledge, including quality control to maintain relationships with service providers, professionally done by each profession department responsibly, do it directionally and structured and always put the customer satisfaction.

To be able to perform the function of professionalism dissemination of knowledge sustainably, required compliance training facilities and Management Information System electronically, a reward system as well fulfillment and regeneration Primary Expert, in all fields of profession. For professions that lack Primary Expert, like Mechanical, Electrical and Civil, (except Geology, Geotechnical as well Building maintenance and care) then made efforts to improve the certification Primary Expert. While in Interior Design, Landscaping Architecture, Illuminati Engineers, Road Safety Engineers and Quality Management System which no expert who has an expertise certificate then made efforts to improve the certification as well recruitment some experts who has an expertise certificate from outside the corporate.

\subsection{Interpretation of Proposition 3}

Making the relevant BSC scheme to accelerate the fulfillment of the corpotare performance is done by the headquarter generally, then downgraded to each profession department and division/ branches, for more be itemized/ specific in manage the work target and its implementation. All of BSC of each department will be monitored with each other electronically so it can be studied and implemented simultaneously and continuously. 
Each department and sub-department formed the constant workflow to achieve the acceleration of corporate performance, that is like the increase in certification and recruiting the new expert, hire the personnel who can strengthen excellence competence which it was all conducted by each profession department. Then continues with cooperation projects, publications, competition, training and research in each department.

2. Technique Interpretation Results of Qualitative Data Analysis

The application of the self-help concept in the respective competence of the profession brings to progress more rapidly, each profession are welcome strengthen the funding, networking, project and resource advantages in all branches and the headquarter only monitors the latest developments. This self-help concept make an each profession create their respective departments, and each strengthen the performance. The performance of each department can be monitored through the BSC in each department, then all of the BSC were integrated back into a whole BSC of a headquarter monitoring.

BSC is made with the matrix concept consist of a growth strategy $[\mathrm{GRW}]$, differentiation strategy [DIFF] and low cost strategy [LOW] in each perspective, complete with financing proportions corresponding Du Pont analysis, then from each of these components made grooves strategy as a critical path or activity relationships between components.

\section{THE CONCLUTION \& SUGGESTONS}

A. Advanced level of fixed expert of profession competence will more add the professional competitive advantage in the market of construction services business. [P1]

This proposition is proven true, be marked by the more needed of professional experts who have a certificate of profession expertise as well be able to explain and responsible for all the work according to competencies.

B. Competency based knowledge management that a good of manage, will be able to improve the knowledge cultural, so can help to achieve the corporate performance. [P2]

This proposition was proved, be marked by the need of management information systems (MIS) as a means of storage and deployment of profession knowledge through intranet and internet who can unite all the corporate employees and customers.

\section{The corporate performance can be monitored and can be} fulfilled through the method of Balanced Score Card. [P3]

This proposition was proved right, be marked by the more needed of a strategy map to know the direction, objectives and achievements of good corporate performance which includes overall competence departments throughout Indonesia.

\section{SUGGESTION}

Recommendations in this regard is to correct the corporate profile by to include growth strategy [GRW], differentiation strategy [DIFF] and low cost strategy [LOW], as well to create strategy map/ Balanced Score Card as appropriate. The improvement corporate profile is as follows:
1) The corporate vision is " to be a consultant corporate of lucrative option in Indonesia and prosperous through excellence in technology management and human resources".

2) Purpose of the corporate is "achieve maximum business growth across Indonesia in the field of construction and non construction in the broadest sense in accordance with the vision and mission of the corporate, by applying the principles of professionalism, reliability, empowerment, synergy, integrity, sustainability and innovative, while strengthening the performance of society together, internal systems are transparent and coordinated, as well its stability is always increasing, highlighting their good ultimate cultural, ethical good, and maintaining a competitive advantage in improving the quality, timeliness and cost-efficient with the risks are minimal and a reliable resource."

3) Target of development is "growth aspec [GRW] is the increased growth in marketing, production and profit by at least $122 \%$ annually. Differentiation aspec [DIFF] is the increased marketing innovation and the production of at least $122 \%$. Low cost aspec [LOW] is the reduction in operating costs by $80 \%$ by way of production efficiency.

4) Human resource criteria is "all experts must be certified $(100 \%)$ considering that all of the projects necessary of profession competence requirements, as well one expert may only hold one project of supervision/ construction management and one project of planning, or 2 projects of planning, in order to create good quality work". As for the need of the permanent profession experts annually are a Primary Experts 155 people, a Middle Experts 381 people and a Beginner Experts 381 people. These are reinforces the first proposition.

5) Criteria for achieving the target of funding is "to minimize carry-over, by accelerating the manufacture reporting and billing on each ongoing project, and do not be late/ in excess of the plan of absorption, as well increasing the number of projects but remain a selective, that is has a good price and a small risk with the value of the project as much as possible well in excess of the target."

6) Criteria for the achievement of performance targets is "to added the EAT value by increasing the amount of revenue (projects) that are profitable and reduce the accounts payable so the EAT value become to rise not because accounts payable, coupled again by way to increase the growth strategy [GRW] and differentiation strategy [DIFF] as well to make a lower production costs [LOW] with normalize the capital to debt ratio into 70: $30 . "$

7) Criteria of corporate system is "need an organizational structure with a clear line of command which contains all sections/ divisions/ branches in complete, as well need to create a competency based knowledge management system of profession well to achieve a competitive advantage of profession competence. "This reinforces the second proposition.

Then need to be made a Balanced Score Card to provide a visual representation of the strategy map that can be read by 


\section{$\triangle$ ATLANTIS PRESS}

all employees who are allowed to have this access. This supports the third proposition. The end result of the Balanced Score Card can be seen in picture 10 below.

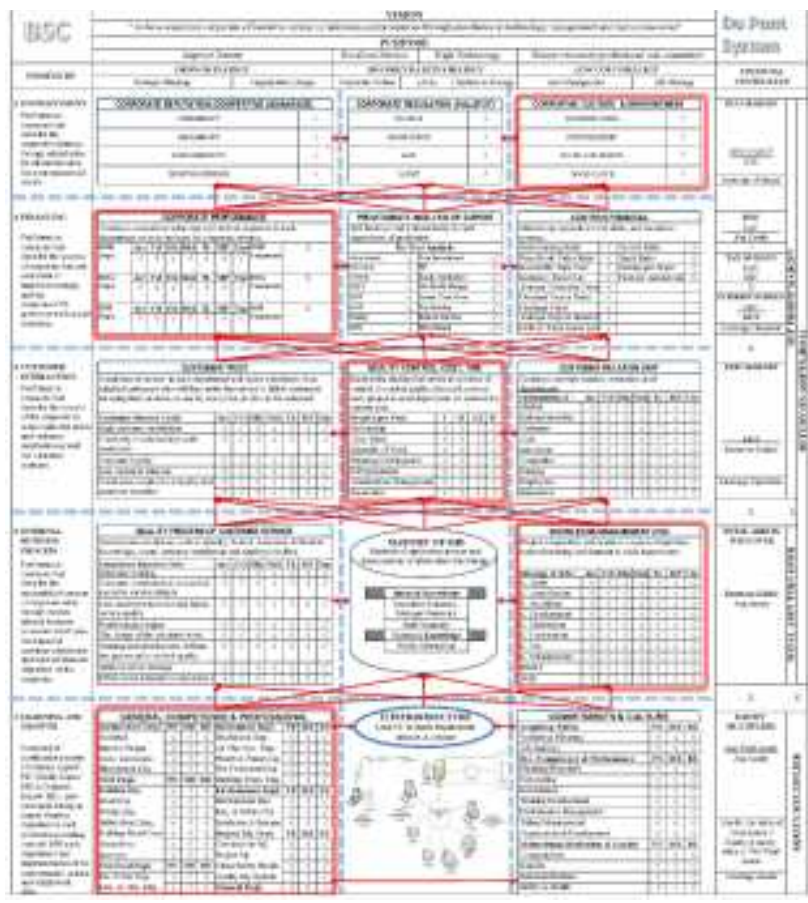

Fig. 10. Balanced Score Card

\section{References}

[1] David, Fred R., 2007, "Strategic Management - Concepts and Cases", $13^{\text {th }}$ Edition. New Jersey. Pearson Education.

[2] Amaratunga, D., Haigh, R., Sarshar, M. \& Baldry, D. 2002, "Application of the Balanced Score-Card Concept to Develop a Conceptual Framework to Measure Facilities Management Performance within NHS Facilities", International journal of health care quality assurance, vol. 15, no. 4, p. 141.

[3] Arora, R. 2002, "Implementing KM - a Balanced Score Card Approach", Journal of Knowledge Management, vol. 6, no. 3, p. 240.

[4] Ferraresi, A.A., Quandt, C.O., dos Santos, S.,A. \& Frega, J.R. 2012, "Knowledge management and strategic orientation: leveraging innovativeness and performance", Journal of Knowledge Management, vol. 16, no. 5,p. 688-701.

[5] LPJK Regulation no. 06 of 2013

[6] Brannick, Joan P. "Balanced Scorecard." Encyclopedia of Industrial and Organizational Psychology. Ed. Steven G. Rogelberg. Vol. 1. Thousand Oaks, CA: SAGE Reference, 2007. 45-46. Gale Virtual Reference Library. Web. 17 Feb. 2015.

[7] Aprianto, Jacob, Sasmito, G.W. 2013, "Annual Performance Planning Information System with Enterprise Architecture Modelling the Secretariat of the Central Java Province Parliament Used Framework Togaf", International Journal of Social Science and Humanity, vol. 3, no. 4, p. 334-n/a.

[8] Htay, S.N.N. \& Salman, S.A. 2013, "Balanced Score Card Approach for Better Shari'ah Corporate Governance",American Journal of Applied Sciences, vol. 10, no. 12, p. 1553-1557.
[9] Davenport, Thomas, H., Prusak, Laurence., 1998, " Du Pont tree formula Working Knowledge", Havard School Press, Boston.

[10] Peter Massingham, 2014, An evaluation of knowledge management tools, ISSN 1367-3270

[11] Hojati, E., Shahin, A. \& Shirouyehzad, H. 2012, "Prioritization of Service Quality Dimension and Performance Indicators Using Analytic Network Process with the Approach of Balanced Score Card; a Case Study", Interdisciplinary Journal of Contemporary Research In Business, vol. 3, no. 9, p. 1190-1198.

[12] Jalaliyoon, N., Bakar, N.A. \& Taherdoost, H. 2012, "Propose a Methodology to Implement Balanced Score Card for Operational Appraisal of Industrial Groups", International Journal of Marketing and Technology, vol. 2, no. 10, hal. 269-278.

[13] Landry, S.P., Wai Yee, C.C. \& Jalbert, T. 2002, "Balanced Scorecard For Multinationals", The Journal of Corporate Accounting \& Finance, vol. 13, no. 6, p. 31-40.

[14] Leonard L. Schleisinger dan James L. Heskett "Breaking the Cycle of Failure in Service" Sloan Management Review 31 (Musim Semi 1991) : 17-28. Copyright 1991 Massachusetts Institute of Technology, dalam Christopher Lovelock, Jochen Wirtz, Jacky Mussry "Pemasaran Jasa Manusia, Teknologi, Strategi Perspektif Indonesia", Jilid 2 Edisi ketujuh, Penerbit Erlangga, 2010.

[15] MacStravic, S. 1999, "A Really Balanced Scorecard", Health Forum journal, vol. 42, no. 3, p. 64-67.

[16] Matzler, K., Renzl, B., Julia M, Herting, S., Mooradian, T.A., 2008, "Personaliy Traits and Knowledge Sharing", Journal of Economic Psychology Vol.29 pg.301-313.

[17] Mcleod, Raymond, JR., 2001, "Sistem Informasi Manajemen", (Diterjemahkan oleh Hardi Sukardi dan Agus Widyantoro), Edisi Ketujuh, Prenhallindo, Jakarta.

[18] Minbaeva, D.B., Prof \& Muratbekova-touron, M. 2013 "Clanism", Management International Review, vol. 53, no. 1, p.109-139.

[19] Nonaka, Ikojiro. Takeuchi, Hirotaka., 2004, "Hitotsubashi on Knowledge Management", John Wiley \& Sons (Asia) Pte. Ltd., Singapore.

[20] Nunn, L.G., Marshall, T. \& "Donald", D.B. 2007, Branded Customer Service: Implementing the Customer Perspective of the Balanced Scorecard to the Ranching Industry, Allen Press Publishing Services, Denver.

[21] O'Brien, James, A., 2005, "Introduction to Information System", $12^{\text {th }}$ Ed. Mc. Graw-Hill Inc., New York.

[22] Probst, G., Raub, S., Romhardt, K., 2000, "Managing Knowledge; Building Blocks for Success", John Wiley \& Sons Ltd, Wesr Sussex, England.

[23] Punniyamoorthy, M. \& Murali, R. 2008, "Balanced Score for the Balanced Scorecard: a Benchmarking Tool", Benchmarking, vol.15, no. 4, p. $420-443$

[24] Rust, R.T. \& Zahorik, A.J. 1993, "Customer satisfaction, customer retention, and market share", Journal of Retailing, vol. 69, no. 2, p. 193.

[25] Schein (1992:12), dalam Bagus, Denny (2015), http://jurnalsdm.blogspot.com/2009/ 04/teori-budaya-organisasi.html.

[26] Scholey, C. 2006, "Risk and the Balanced Scorecard", CMA Management, vol. 80, no. 4, p. 32-35.

[27] Sekaran, Uma and Roger Bougie, 2000, "Research Methods for Business", $5^{\text {th }}$ Edition. New York. Jhon Wiley \& Sons, Inc.

[28] "Soobest.com; E-commerce Quantitative Performance Management Tool - Balanced Score Card BSC", 2012, Investment Weekly News, , p. 366.

[29] Tiwana, Amrit., 2000, "The Knowledge Management Toolkit", New Jersey, Prentice Hall, Inc.

[30] Tobing, Paul, L., 2007. "Knowledge Management ; Konsep, Arsitektur dan Implementasi", Edisi Pertama, Cetakan Pertama. 